\title{
Impact of praziquantel baiting on intestinal helminths of foxes in southwestern Germany
}

\author{
T. ROMIG ${ }^{1}$, B. BILGER ${ }^{1}$, A. DINKEL ${ }^{1}$, M. MERLI, D. THOMA ${ }^{1}$, R. WILL ${ }^{1}$, U. MACKENSTEDT $^{1}$, \\ R. LUCIUS ${ }^{2}$
}

${ }^{1}$ FG Parasitologie, University of Hohenheim, Stuttgart, Germany; ${ }^{2}$ Chair of Molecular Parasitology, Humboldt University, Berlin, Germany

\begin{abstract}
Summary
Fox baits containing $50 \mathrm{mg}$ praziquantel were distributed by aircraft in a $3000 \mathrm{~km}^{2}$ area of southwestern Germany from 1995 to 1999.20 baits $/ \mathrm{km}^{2}$ were initially distributed at intervals of six to twelve weeks. Starting from a prebaiting prevalence of $64 \%$ (95\% C.I. $59-69)$, a level of $15 \%$ (C.I. $10-21$ ) was reached after 18 months. Further decreasing the frequency and discontinuing the bait distribution caused a surge to $55 \%$ (C.I. 49 - 61) within 36 months. Other cestode species (Taenia spp., Mesocestoides spp.) showed similar responses, while the prevalence of ascarid nematodes did not decline during baiting. New infections of fox cubs with E. multilocularis, but not with other cestodes, drastically decreased after one year. Prevalences of fox helminths in an external control area remained stable. Our data suggest that repeated praziquantel treatment of free ranging foxes is suitable to reduce the prevalence of E. multilocularis in a large area.
\end{abstract}

Key words: Echinococcus multilocularis; alveolar echinococcosis; epidemiology; control; praziquantel; bait

\section{Introduction}

Alveolar echinococcosis (AE), caused by the fox tapeworm Echinococcus multilocularis, is the most severe parasitic zoonosis in Europe (Pawlowski et al., 2001). Curative treatment of AE by radical surgery is possible only in an early stage of the disease, while the majority of patients is diagnosed in an advanced stage when more than one liver lobe is involved. In such cases, continuous chemotherapy with benzimidazoles (albendazole or mebendazole) is the treatment of choice. This will, in most cases, inhibit the growth of the parasitic lesion, but will not lead to cure. Thus, lifelong chemotherapy is the rule, with an estimated cost of USD 300,000 per patient per life (Romig et al., 1999a). For patients with adverse reactions to benzimidazoles there is currently no treatment option. Although the number of human AE cases in Europe is still small, this situation appears to be changing. Following a drastic increase of the size of European fox populations which had occurred during the 1990 s, and a temporally correlated increase of E. multilocularis prevalence in foxes (Romig et al., 1999b; Jenkins et al., 2005), the annual incidence of human AE in Switzerland has risen from 0.10 per 100,000 population during 1993 - 2000 to 0.26 per 100,000 during 2001 - 2005 (Schweiger et al., 2007). Apart from the density of infected foxes (which was estimated to have increased by the factor 10 since the 1980s - Romig et al., 1999b), an increasingly close contact between wild foxes and humans due to newly established urban fox populations is likely to be responsible for this development (Deplazes et al., 2004). In Europe, E. multilocularis is predominantly transmitted by foxes. Domestic dogs and cats are sporadically found infected, but their quantitative contribution to the transmission cycle of this parasite is minor. Although prevention of dog infection is believed to be an important means to reduce the risk for $\mathrm{AE}$ in humans, any control measure with the aim to interrupt or weaken the life cycle of $E$. multilocularis has to be targeted at foxes (Ito et al., 2003). This could, in theory, be done either by reducing the population density of host animals (e.g. by increased hunting pressure), or by reducing the parasite population by anthelmintic treatment of foxes. Conventional hunting techniques have not prevented the drastic population increase following the elimination of rabies, and, as E. multilocularis was successfully transmitted even during the rabies period before 1990, there is no indication that even intensified hunting has the potential to reduce the fox 
population to a level where the life cycle of E. multilocularis is interrupted.

A first trial with anthelmintic treatment of wild foxes was done by Schelling et al. (1997) in southwestern Germany. The cestodicidal drug praziquantel was administered in baits in densities of $15-20$ baits $/ \mathrm{km}^{2}$ in a $566 \mathrm{~km}^{2}$ study area. After six rounds of baiting during a 14-month period, the prevalence in foxes had decreased from $16-52 \%$ (CI $95 \%$ ) to $2-7 \%$. An application on a larger scale, with bait distribution by aircraft, was done in northeastern Germany in a study area of $5000 \mathrm{~km}^{2}$, enclosing two circumscribed endemic foci within a low endemicity region (Tackmann et al., 2001). Bait distribution was done at six-week intervals for one year, followed by a second year with three-month intervals. The prevalence could be reduced from $16-27 \%$ to $2-6 \%$ in the ende-mic foci, and from 4 $-7 \%$ to $0-1 \%$ in the low ende-micity area. Similar results - drastic reduction, but no eli-mination - were obtained in two studies on smaller areas in Japan (reviewed in Ito et al., 2003). In a small-scale ap-proach targeting urban foxes, Hegglin et al. (2003) distri-buted 50 baits per $\mathrm{km}^{2}$ monthly in areas of 1 and $6 \mathrm{~km}^{2}$. The proportion of coproantigen-positive fox faecal samples declined from 39 $\%$ to $5 \%$, and from $67 \%$ to $2 \%$, respect-tively, in the course of 18 months. No data, however, are available on the long-term effect of praziquantel-baiting on the prevalence of E. multilocularis in foxes, nor on the im-pact of this method on other intestinal helminths of foxes. In this study, we present the impact of large-scale praziquantel baiting on the helminth fauna of foxes in an area of southwestern Germany highly endemic for E. multilocularis, and report on the effect during a follow-up period after discontinuation of baiting.

\section{Material and Methods}

\section{Study area and sampling}

The study was conducted from May 1995 to April 2001 in a $3,400 \mathrm{~km}^{2}$ (reduced to $3,000 \mathrm{~km}^{2}$ from January 1998) area of the central Swabian Jura in the federal state of Baden-Württemberg (Germany) (Fig. 1). Control area (without baiting) was a $2,440 \mathrm{~km}^{2}$ area in the northern part of the state (Fig. 1). During the entire study period, foxes in the baiting area were coninuously sampled from local hunters and examined for intestinal helminths. In the baiting area, sampling was - for practical reasons - restricted to $556 \mathrm{~km}^{2}$, which consisted of the central part and three corridors towards the periphery of the baiting area (Fig. 2). In the control area, sampling was done by collecting foxes from the entire area, which had been sent to the governmental veterinary laboratories in Heidelberg in the context of a rabies monitoring programme. Sample size for the baiting area was a total of 4,740 foxes (mean 790 per year), which amounts to a sample densitiy of 1.4 foxes per $\mathrm{km}^{2}$ per year in the sampling area. This is well below the hunting bag of private fox hunters $\left(2-3\right.$ foxes per $\mathrm{km}^{2}$ in this region), and is not expected to constitute a confounding factor by decreasing the population densitiy.
From the control area, we obtained a total of 2,657 foxes (mean 443 per year), a sampling density of 0.2 per $\mathrm{km}^{2}$ per year.

\section{Diagnosis}

Fox carcasses were obtained frozen at $-20{ }^{\circ} \mathrm{C}$, transferred to a biohazard laboratory and further processed according to biohazard legislation (biosafety level L3). Foxes were allowed to thaw for 36 hours and were examined for large helminths by macroscopic inspection of the entire small intestine, and for small helminths by the intestinal smear technique (Eckert et al., 2001). For Mesocestoides spp., Taenia spp., ascarid nematodes (Toxocara and Toxascaris), recording was qualitative (present or absent). Determination was not done to species level; with Taenia, subsamples were invariably identified as $T$. crassiceps or $T$. polyacantha. For E. multilocularis, recording was semiquantitative (number of worms seen in the smears under 12x magnification).

\section{Analysis}

To obtain sufficient sample sizes in different strata, prevalence was expressed as period prevalence combining data from three- or six-month periods. Stratification was further done according to space (different areas within the sampling areas) and fox age (cubs $\leq 3$ months age, juveniles $\leq 6$ months age, adult $>6$ months age). Confidence intervals were determined according to Cannon \& Roe (1982).

\section{Baits and bait distribution}

Fox baits containing $50 \mathrm{mg}$ praziquantel were used either as Droncit ${ }^{\circledR}$ bait (Bayer AG, Leverkusen), or in combination with rabies vaccine (Rabifox-Droncit ${ }^{\circledR}$ bait, IDT $\mathrm{GmbH}$, Rosslau). The baits were distributed by aircraft at a density of 20 baits per $\mathrm{km}^{2}$. In total, there were 18 bait distribution campaigns. Time intervals between baiting was six weeks (October 1995 to March 1997), three months (May 1997 to March 1998) and six months (May 1998 to October 1999).

\section{Results}

\section{Echinococcus multilocularis}

Bait distribution in six-week intervals lead to a reduction of the observed prevalence from initially $59-69 \%$ (CI 95 $\%$ ) to less than $20 \%$ within 12 months of baiting (Fig. 3). This level stabilized with no further tendency for decrease, leading to a prevalence of $13-24 \%$ (CI $95 \%$ ) during the baiting months $15-21$. After increasing the intervals between baiting to three months, no prevalence change was observed: during the period $8-14$ months after the introduction of the three-month schedule, the prevalence was still $10-21 \%$ (CI. $5 \%$ ) (Figs. 3, 4, 5). However, the consecutive change of baiting intervals to six months coincided with a prevalence increase to $31-41 \%$ (CI $95 \%$ ) during months $15-21$ after the introdution of that schedule. During months $13-18$ after the last bait distribution, 
the prevalence had increased to $49-61 \%$ (CI $95 \%$ ) (Figs. $3,6)$. The changes of prevalence were closely similar in

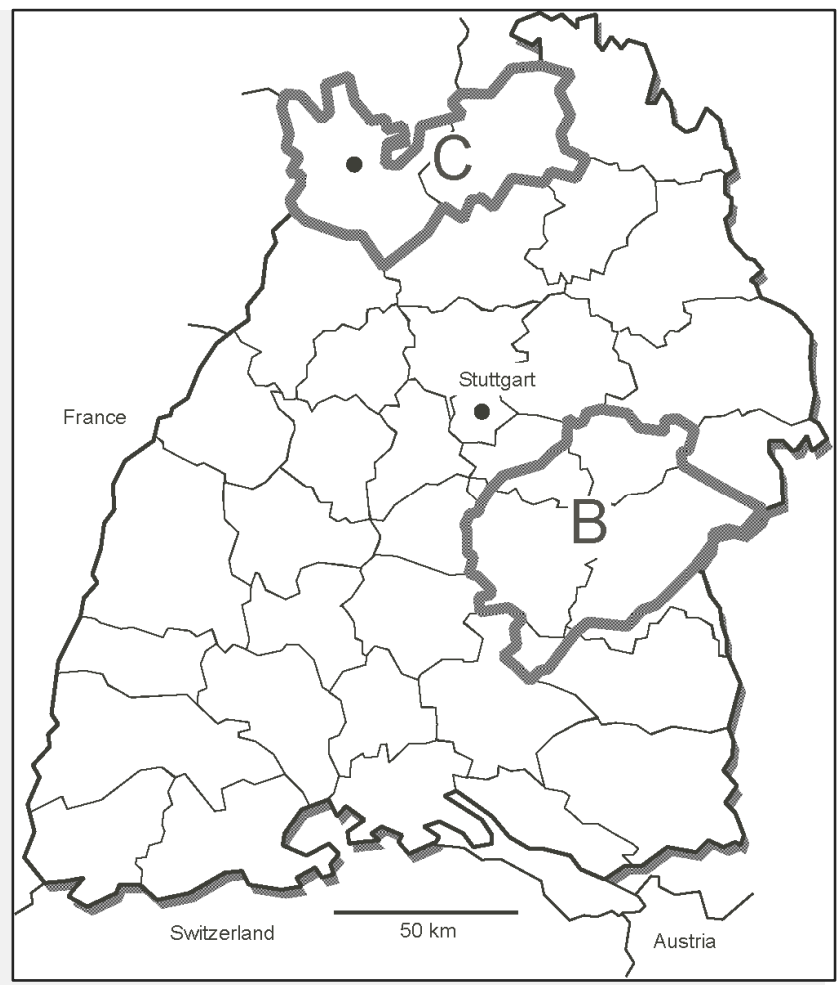

Fig. 1. Map of Baden-Württemberg (federal state in the Southwest of Germany), showing the baiting area (B) and control area (C)

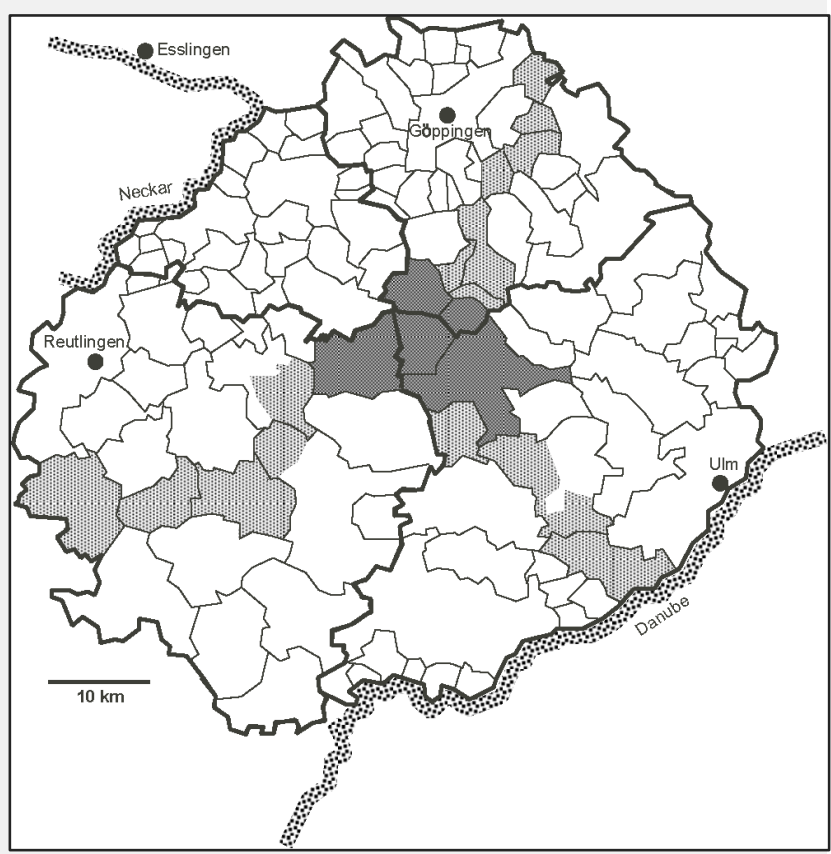

Fig 2. Map of the baiting area (as reduced by January 1998), showing central and peripheral sampling areas (light and dark shading)

the central and peripheral parts of the study area (Figs. 4, $5,6)$. During the entire study period, no significant preva- lence change was oberserved in the control area, which was stratified for two adjacent sub-areas with different pre-

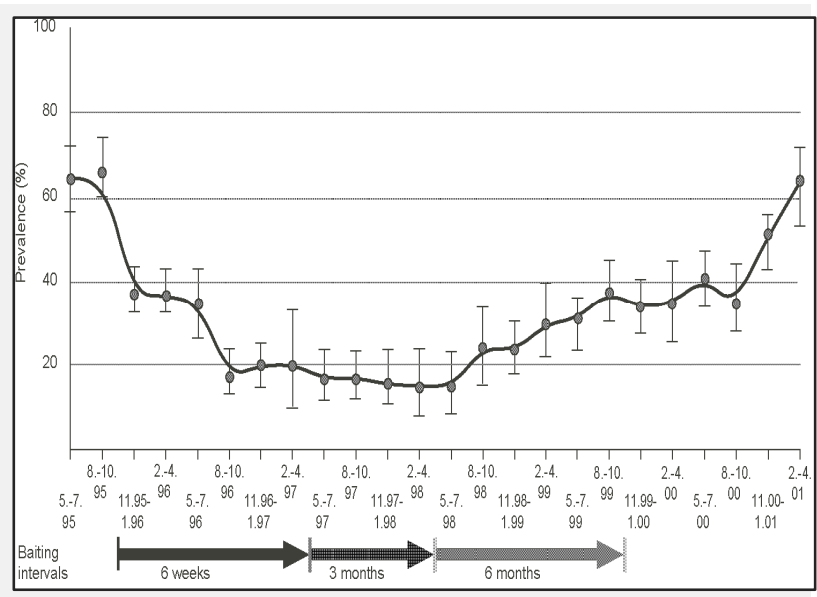

Fig. 3. Temporal development of prevalence estimates of $E$. multilocularis in foxes in all sampling areas of the baiting area (three-month period prevalences with $95 \%$ confidence intervals)

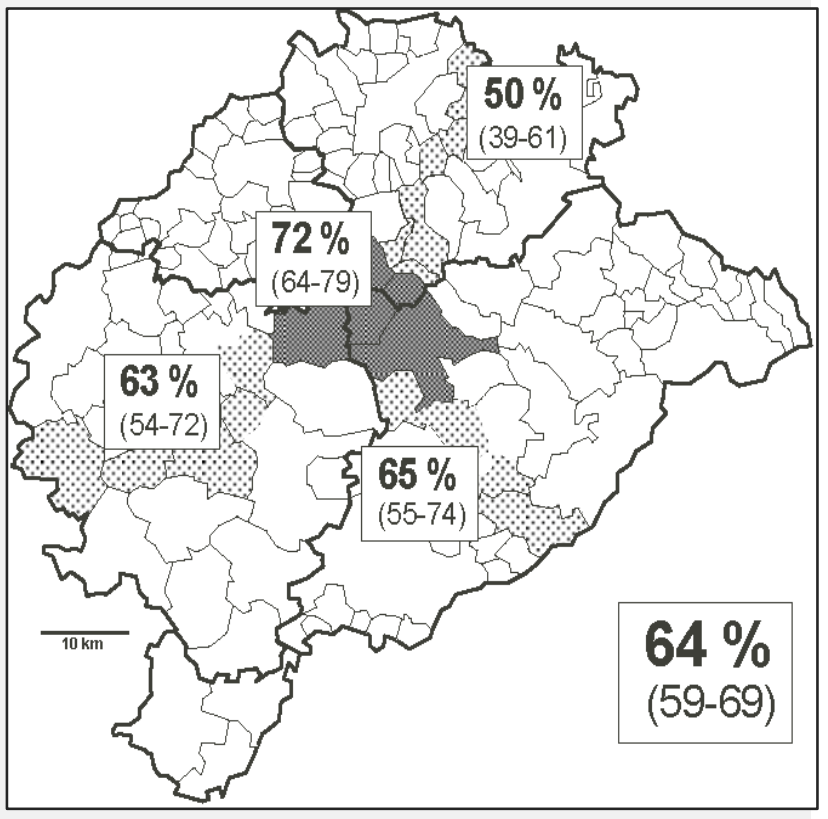

Fig. 4. Prevalence distribution of E. multilocularis before the start of praziquantel baiting (May to October 1995) in four parts of the sampling area (in brackets: $95 \%$ confidence intervals)

valence levels (Fig. 7).

During the summer months (April to September) foxes were strafied for age. During all periods of the study, juvenile foxes were more frequently infected and had larger numbers of worms, whereas the proportion of different infection intensities remained similar (Fig. 8). It was also apparent that prevalence reduction was more pronounced in adult foxes than in juveniles during the baiting period. Of special interest is the prevalence in fox cubs in the period from April to June with their limited mobility and limited access to baits: prevalence reduction in this age group 
showed a one-year delay in comparison with adults (Fig. 9).

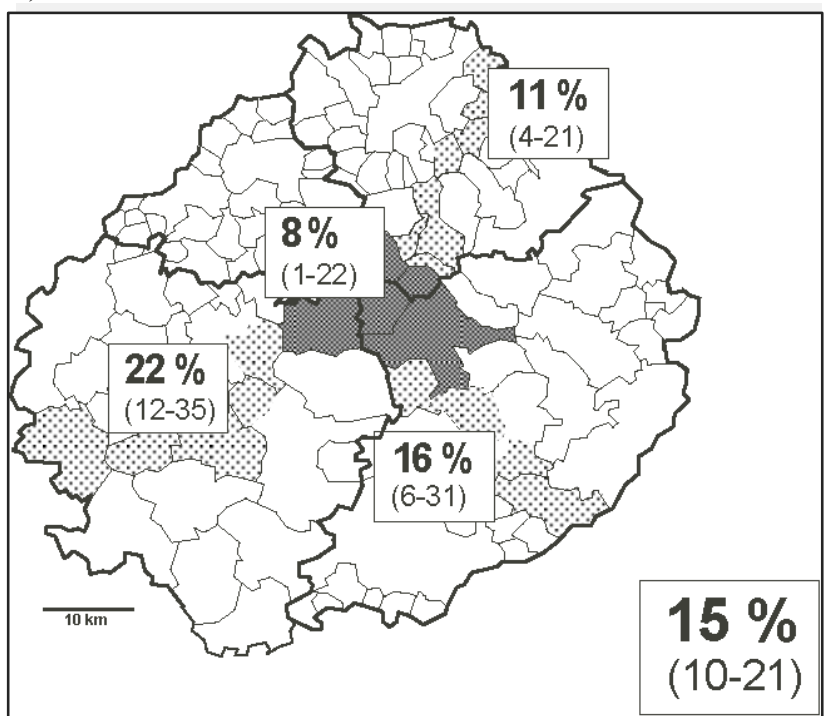

Fig. 5. Prevalence distribution of E. multilocularis 8 - 14 months after the three-monthly baiting schedule was started (February to July 1998) in four parts of the sampling area (in brackets: $95 \%$ confidence intervals)

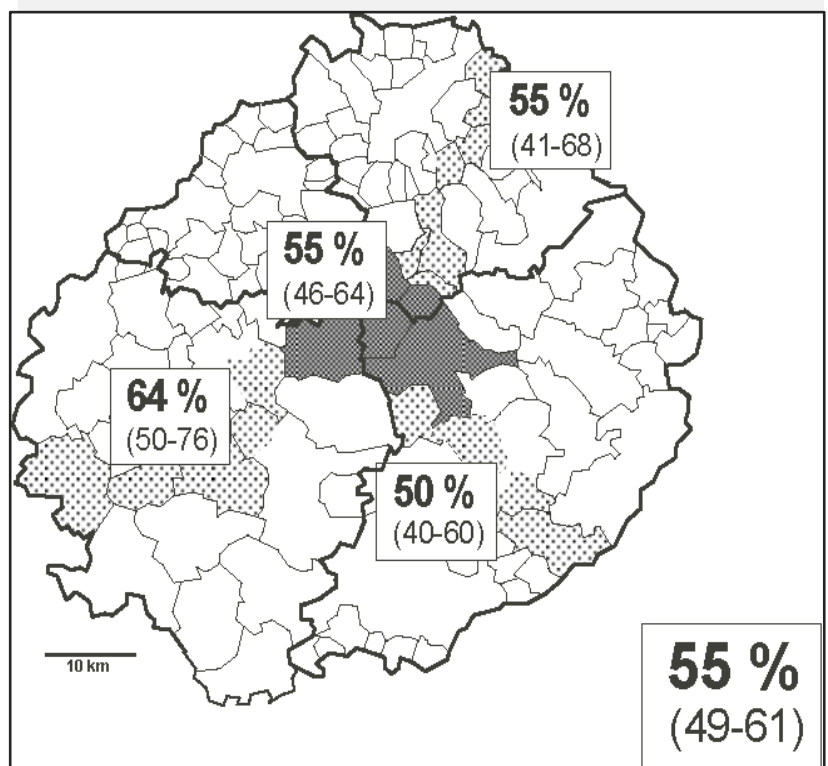

Fig. 6. Prevalence distribution of E. multilocularis 13 - 18 months after discontinuation of baiting (November 2000 to April 2001) in four parts of the sampling area (in brackets: $95 \%$ confidence intervals)

\section{Other cestodes}

In comparison with E. multilocularis, the reduction of Taenia spp. prevalence during praziquantel baiting was less pronounced, and the recovery to (and above) the pre-baiting level was achieved far earlier than with E. multilocularis. When looking at the age stratification, the reducetion of prevalence is almost entirely due to the effect on adult foxes, while the prevalence in fox cubs remained al- most unchanged (Figs. 10, 11). The overall response of Mesocestoides spp. rather follows that of E. multilocularis,

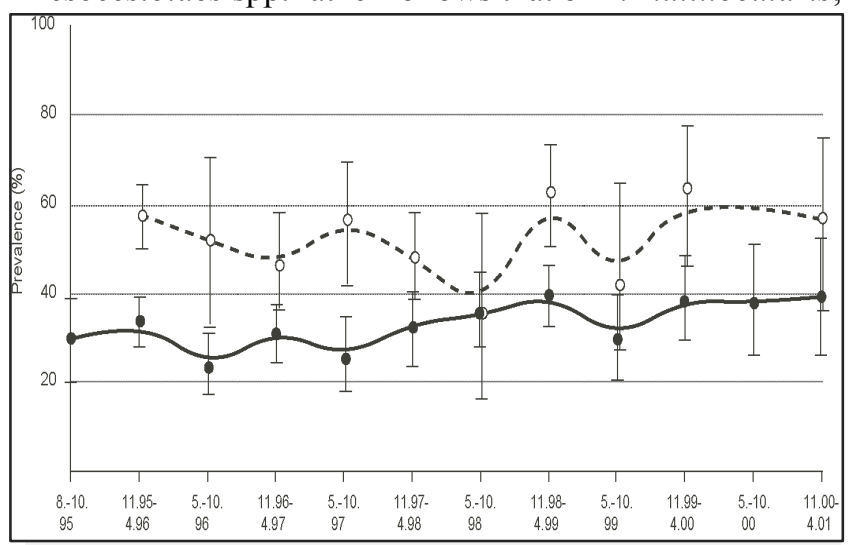

Fig. 7. Temporal development of prevalence estimates of $E$. multilocularis in foxes in the control area (six-month period prevalences with $95 \%$ confidence intervals). Black dots, black line: counties Rhein-Neckar, Mannheim and Heidelberg. White dots, dotted line: county Neckar-Odenwald

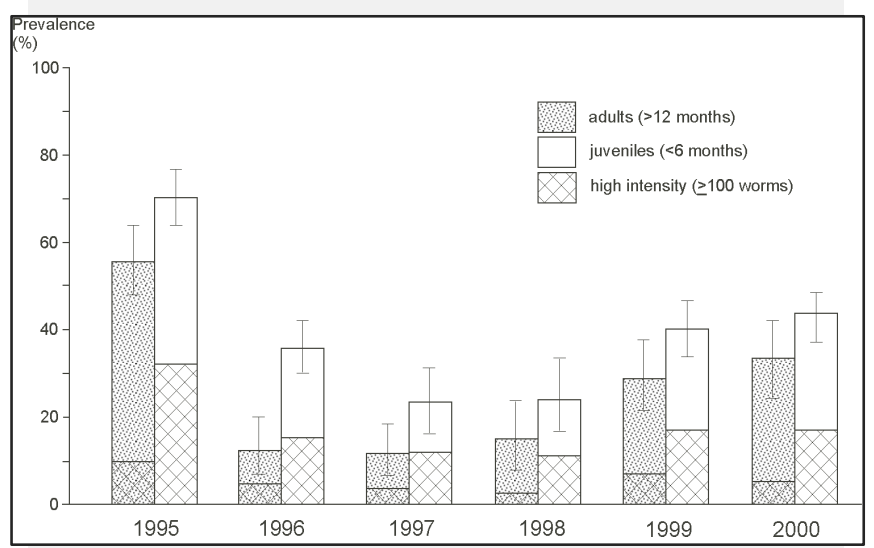

Fig. 8. Age-stratified prevalence of E. multilocularis in adult and juvenile foxes (April to September). Worm burden is classified in two categories (high $>100$ worms, low $<100$ worms). Worm numbers are those counted on the slides of the mucosal smears (ITS method), not the total number of worms present in the intestine. Sixmonth period prevalences with $95 \%$ confidence intervals

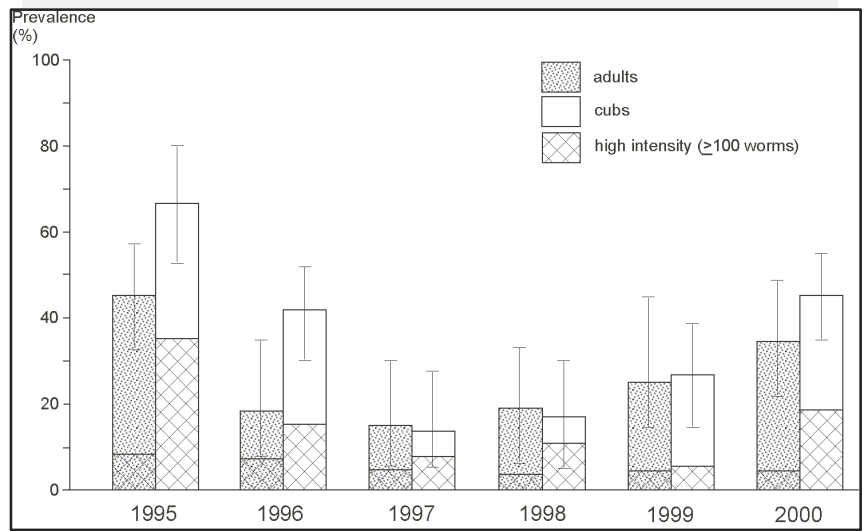

Fig. 9. Age-stratified prevalence of E. multilocularis in adult foxes and fox cubs (April to June). Worm burden is classified in two categories (high $\geq 100$ worms, low $<100$ worms). Worm numbers are those counted on the slides of the mucosal smears (ITS method), not the total number of worms present in the intestine. Three-month period prevalences with $95 \%$ confidence intervals 


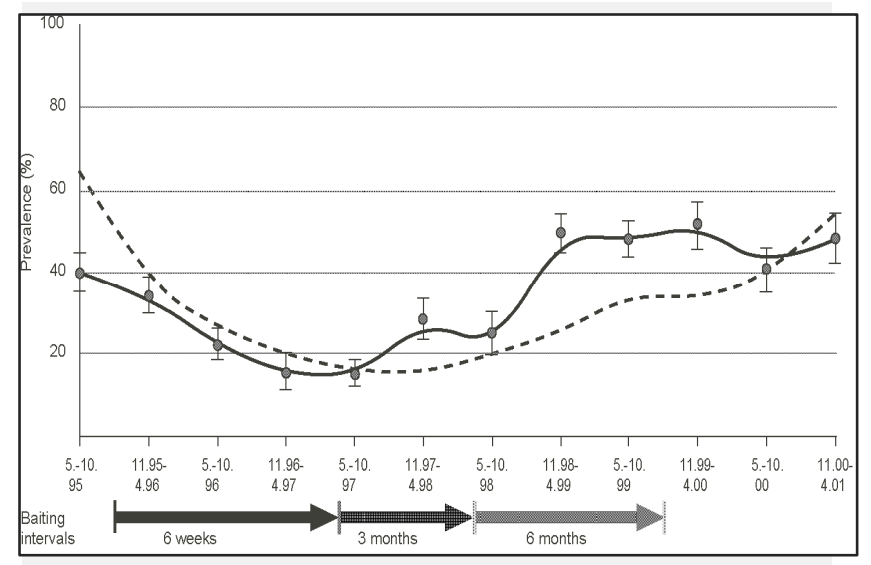

Fig. 10. Temporal development of prevalence estimates of Taenia spp. in foxes in all sampling areas of the baiting area (six-month period prevalences with $95 \%$ confidence intervals). Dotted line: prevalence of E. multilocularis

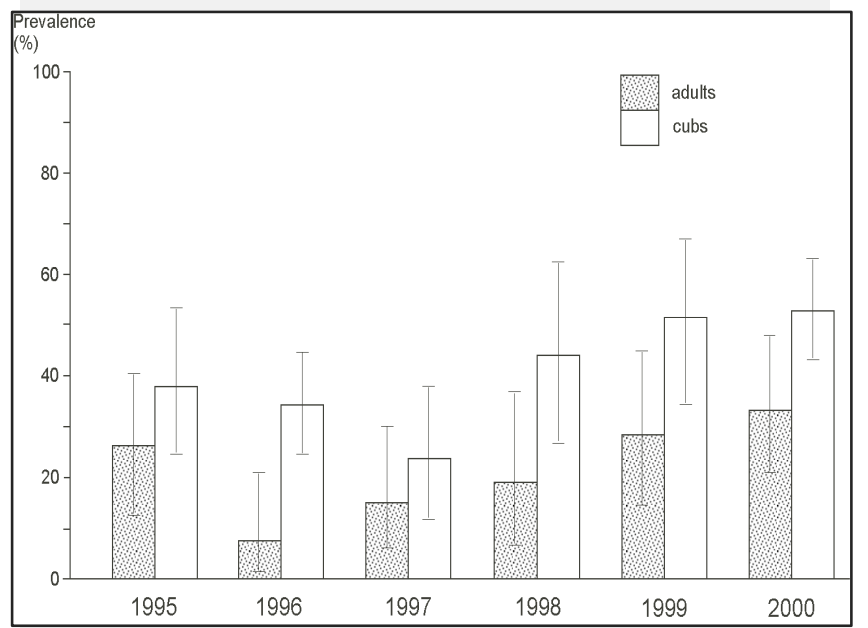

Fig. 11. Age-stratified prevalence of Taenia spp. in adult foxes and fox cubs (April to June). Three-month period prevalences with 95 $\%$ confidence intervals

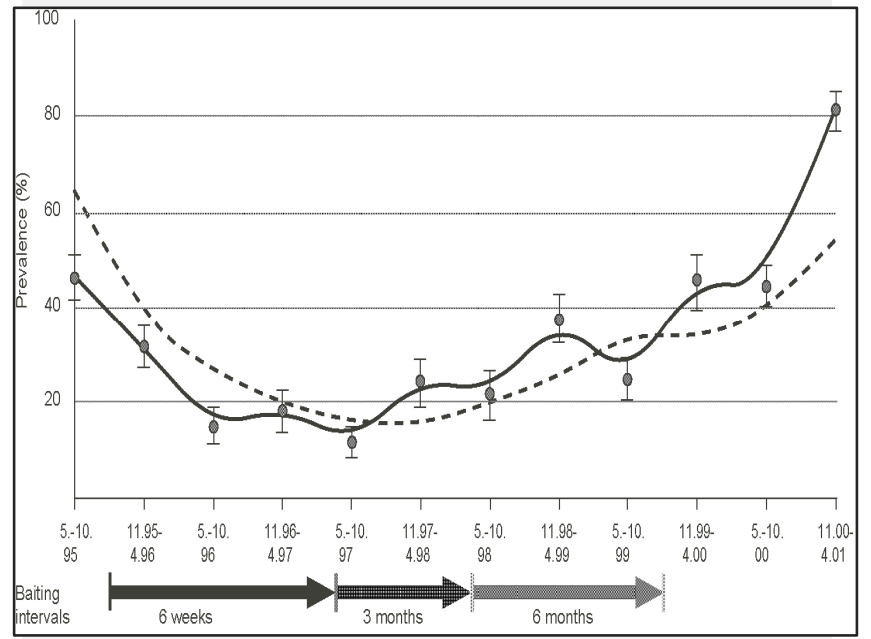

Fig. 12. Temporal development of prevalence estimates of Mesocestoides spp. in foxes in all sampling areas of the baiting area (six-month period prevalences with $95 \%$ confidence intervals).

Dotted line: prevalence of $E$. multilocularis

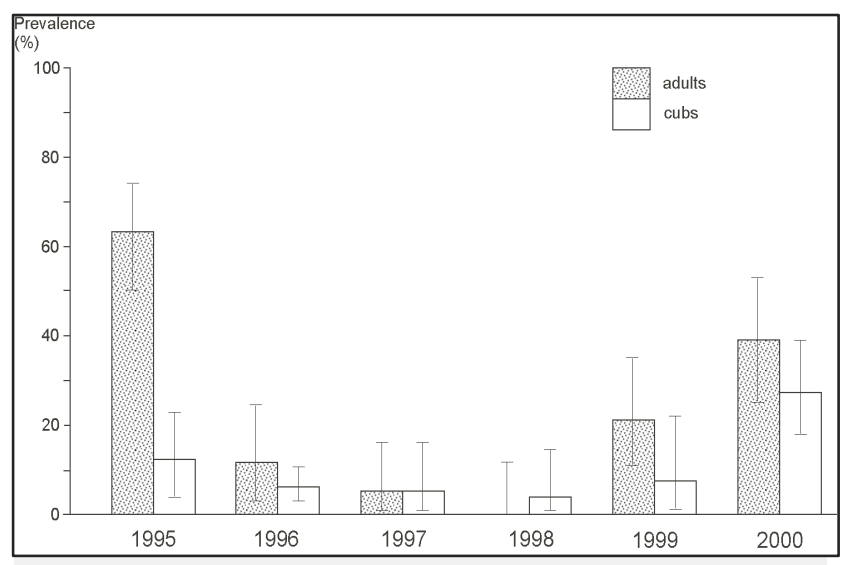

Fig. 13. Age-stratified prevalence of Mesocestoides spp. in adult foxes and fox cubs (April to June). Three-month period prevalences with $95 \%$ confidence intervals

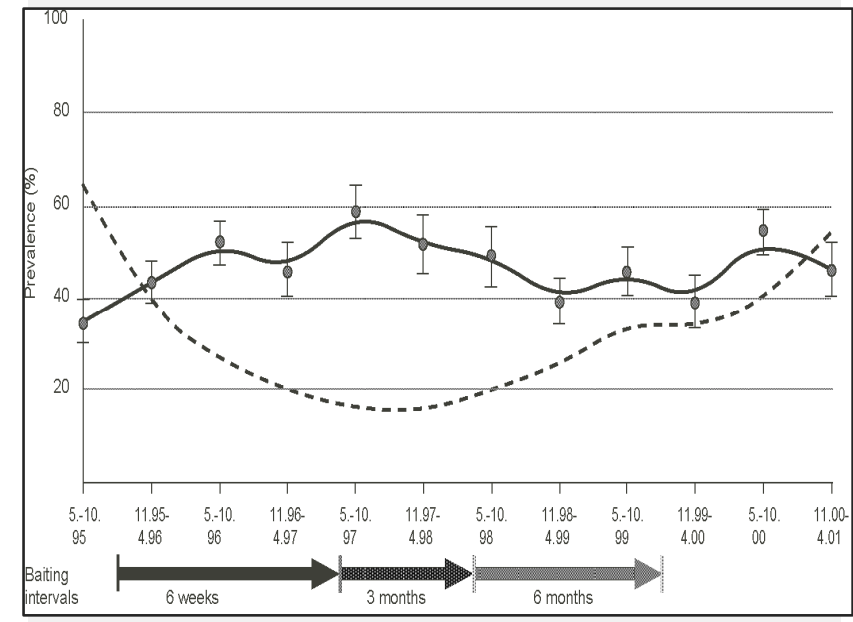

Fig. 14. Temporal development of prevalence estimates of ascarid nematodes (Toxocara and Tosxascaris) in foxes in all sampling areas of the baiting area (six-month period prevalences with $95 \%$ confidence intervals). Dotted line: prevalence of $E$. multilocularis

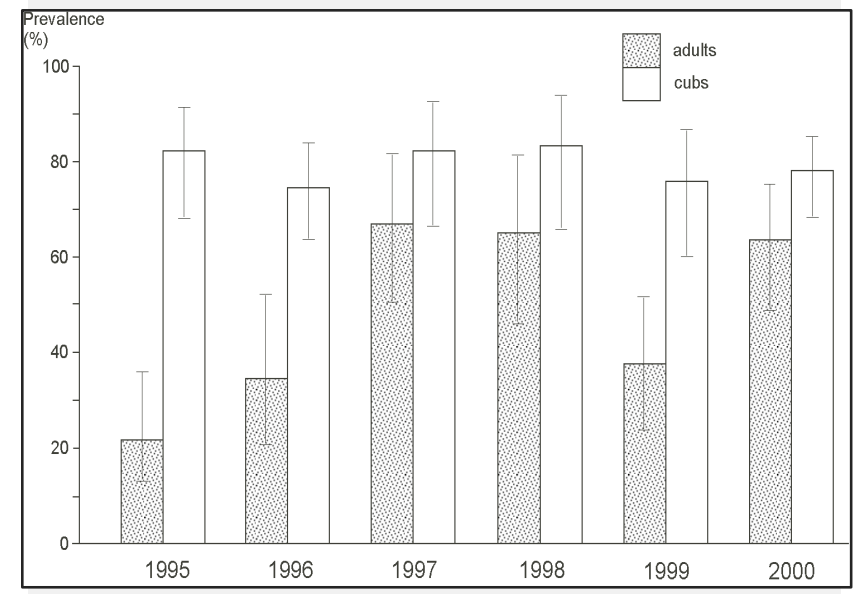

Fig. 15. Age-stratified prevalence of ascarid nematodes (Toxocara and Toxascaris) in adult foxes and fox cubs (April to June). Threemonth period prevalences with $95 \%$ confidence intervals 
but the age-stratified results differs totally. Before the influence of praziquantel baiting, most Mesocestoides infections were found in adults (in contrast to Echinococcus and Taenia). Again, the infection rate of adults was drastically reduced during the baiting period, while it hardly changed in fox cubs (Figs. 12, 13).

\section{Ascarids}

The prevalence of ascarids increased during the period of baiting, coinciding with decreased infection rates of cestodes. This effect was due to a larger proportion of infected adult foxes, while the prevalence in cubs remained unchanged (Figs. 14, 15).

\section{Discussion}

\section{E. multilocularis}

We could show that the prevalence of E. multilocularis substantially decreased after repeated air distribution of praziquantel baits in a high endemicity area. After seven baiting campaigns in the course of twelve months the prevalence was reduced by approximately $75 \%$, but did not decrease further. However, only six months after this level was reached, the six-weekly baiting intervals had to be increased to three months due to financial constraints. Whether or not a further decrease could have been achieved by continuing with shorter baiting intervals remains speculative. It is, however, suggestive to look at infection rates of fox cubs of less than three months of age. In this age group, the radius of movement is still small, and access to baits is unlikely. Thus, the prevalence in cubs may serve as an index for the presence of infected rodent intermediate hosts. In the first year of baiting this was still high (Fig. 9), and the general prevalence decrease was apparently caused by the increased mortality of the worm population in adult foxes due to anthelmintic treatment. In the second year, infection of fox cubs was drastically decreased (suggesting a similarly drastic decrease of re-infection of adult foxes), which is likely to be caused by a lower number of infected rodents. Reduced prevalence in rodents, in turn, should have been caused by two factors: fewer eggs were shed by foxes due to praziquantel baiting, while eggs persisting in the envirnment from the pre-baiting period would have gradually decayed. This is in agreement with the observation that $E$. multilocularis eggs survive for less than one year in the environment under favourable conditions (Veit et al., 1995). This reduced re-infection rate of foxes may be the reason, why the general prevalence level remained low despite the reduced baiting frequency. A further decrease of baiting frequency to once in six months was accompanied by a prevalence increase in all age groups. This increase, initially slow, accelerated one year after the last distribution of baits, and the prevalence resurged to that of the pre-baiting period a further six months later.

The prevalence decrease observed in the initial two years of this study is in accordance with previously published data (Schelling et al., 1997, Tackmann et al., 2001, Ito et al., 2003, Hegglin et al., 2003), which were, with exception of the first study, obtained under different epidemiological conditions (low endemicity level, small-scale, or urban area). In all studies, a drastic prevalence reduction was observed. Complete interruption of the life cycle of the parasite could not yet be demonstrated, although hitherto published studies are characterized by rather short baiting periods of up to two years and do not include follow-up data. In the present study, the transmission of $E$. multilocularis persisted throughout the baiting period. Immigration of infected foxes from outside the study area appears to play a marginal role - if any -, as the prevalences during the course of the study were closely similar in central and peripheral parts of the baiting area. In addition, fox cubs of $\leq 3$ months were found infected, although at a much reduced rate, throughout the baiting period. Various factors might have contributed to the peristence of the life cycle. (1) The period of high baiting frequency may have been terminated too early, as a reduced re-infection rate only became apparent in the second year. (2) The number of baits may not have been adequate. The bait density of 20 per $\mathrm{km}^{2}$ was chosen from previous experience with praziquantel baits (Schelling et al., 1997) and from rabies campaigns. However, the population density of foxes in the study region - as in other areas of Europe had increased drastically during the 1990s (Romig et al., 1999b). (3) Bait distribution by air is restricted to open areas without human settlement, as bait must not be distributed closer than $300 \mathrm{~m}$ from buildings. Foxes, however, increasingly utilize towns and villages (,urban foxes') (Gloor et al., 2001). Although such foxes are less frequently infected with E. mutlilocularis than those in rural habitats, their population density is often higher, which may amount to an equal, or even larger, number of infected foxes per area (Deplazes et al., 2004). In the present study, a large proportion of these foxes had homeranges restricted to areas without bait distribution (Thoma et al., 2004), which may have contributed to the persistence of autochthonous transmission. There is a number of additional variables, which could be used to optimize the distribution schedule. Specific targets could be juvenile foxes, which showed a higher prevalence and - more importantly - had higher infection intensities than adults during the summer months. Increased baiting frequency during this period may enhance the efficiency of the method. The impact of these variables cannot be evaluated by large-scale field trials. Instead, mathematical models will in future be important tools to optimize baiting schedules (Hansen. et al., 2003).

\section{Other helminths}

The development of total prevalence of the praziquantelsensitive cestodes Taenia spp. and Mesocestoides spp. rather resembled that of E. multilocularis. However, when looking at the age stratification during the cub rearing months, differences became apparent. With Taenia, the prevalence decrease seemed largely due to the anthelmintic effect on the adult worms. Looking at the re-infection rate (inferred from the prevalence in fox cubs - Fig. 11), only a 
slight decrease is notable in the second year (with broadly overlapping confídence intervals). Apparently, the life cycle of Taenia is less sensitive to an increased worm mortality, and the extent of anthelmintic treatment in this study may not have substantially reduced the number of infections in rodents. This can serve as an explanation of the rapid resurge of Taenia prevalence to the pre-baiting level, which occurred two years earlier than with Echinococcus. This observation is in agreement with Gemmell \& Lawson (1986), who demonstrated a higher resilience of $T$. ovis and $T$. hydatigena in comparison with $E$. granulosus against control measures in dogs. With Mesocestoides, prevalence decrease and subsequent increase follow more closely those of E. multilocularis, although a prevalence rise at the end of the study to almost double the pre-baiting figure remains unexplained. The seasonal dynamics of Mesocestoides - whose transmission cycle is still enigmatic (Loos-Frank, 1991) - appear different from Taenia. Even without the influence of praziquantel, fox cubs show much lower infection rates than adults. This is in stark contrast to Echinococcus and Taenia and could be explained by a generally lower density of infected intermediate hosts, and/or by seasonal transmission peaks in months other than April to June. As with Taenia, the baiting impacted largely on the prevalence in adult foxes, while no significant change was observed in fox cubs throughout the study period. As expected, ascarid nematodes, which are not sensitive to praziquantel, showed no prevalence decrease during the baiting period. Rather, ascarid prevalence increased in those periods with the lowest prevalence of cestodes (years two and three). Whether or not this is the result of reduced interspecific competition among large intestinal helminths is not known. However, the prevalence increase in years 2 and 3 was not due to increased incidence, as the prevalence in fox cubs remained unchanged. Rather, a larger proportion of foxes appears to have kept the ascarid worms into adulthood than in the period before baiting.

\section{Conclusion}

Our data show, that praziquantel baiting has a drastic effect on E. multilocularis and other cestodes of foxes, but that even local elimination of the parasite transmission is not achieved under the described regimen. E. multilocularis, however, is the only helminth of foxes where - with time delay of one year - a reduced re-infection could be demonstrated. This instability of the life cycle to increased mortality of adult worms provides a perspective for a more substantial reduction, or elimination, of the parasite transmission using modified baiting schedules.

\section{Acknowledgement}

The study was financially supported by the Ministerium Ländlicher Raum, Baden-Württemberg (Forschungsvorhaben ,Bekämpfung des Fuchsbandwurms', 1.12.1994 30.4. 2001). We are grateful for support of various kind by the state veterinary laboratories in Heidelberg and Stutt- gart, and by a large number of local community administrators, veterinarians, and hunters.

This article was not independently peer-reviewed and is published as submitted by the author.

\section{References}

CANNON, R. M, RoE, R.T. (1990): Krankheitsüberwachung in Tierbeständen (Infection control in life stock) (deutsche Übersetzung und Bearbeitung von RJ Lorenz). AID, Bonn Deplazes, P., Gloor, S., Hegglin, D., Romig, T. (2004): Wilderness in the city - the urbanization of Echinococcus multilocularis. Trends in Parasitology, 20: $77-84$

Eckert, J., Deplazes, P., Craig, P. S., Gemmell, M. A, Gottstein, B., Heath, D., Jenkins, D. J., KamiYA, M., LIGHTOWLERS, M. (2001): Echinococcosis in animals: clinical aspects, diagnosis and treatment. In ECKERT, J., Gemmell, M. A., Meslin, F. X., PAwlowsi, Z. S. (Eds.): WHO/OIE manual of echinococcosis in humans and animals: a public health problem of global concern. World Organisation for Animal Health, Paris, pp. 72 - 99

GeMmell, M. A., LAwson, J. R. (1986): Epidemiology and control of hydatid disease. In THOMPSON R. C. A. (Ed.): The biology of Echinococcus and hydatid disease. George Allen \& Unwin, London, pp. 189 - 216

Gloor, S., Bontadina, F., Hegglin, D., Deplazes, D., BREITENMOSER, U. (2001): The rise of urban fox populations in Switzerland. Mamm. Biol., 66: 155 - 164

Hansen, F., Thulke, H. H., Jeltsch, F. (2003): Simulationsmodelle zur Planung von Strategien in der Bekämpfung von Wildtiererkrankungen. Forum Geoökol., 14: 20 22

Hegglin, D., Ward, P. I., Deplazes, P. (2003): Anthelmintic baiting of foxes against urban contamination with Echinococcus multilocularis. Emerg. Infect. Dis., 9: 1266 1272

Ito, A., Romig, T., TAKahashi, K. (2003): Perspective on control options for Echinococcus multilocularis with particular reference to Japan. Parasitology, 127: S159 S172

Jenkins, D. J., Romig, T., Thompson, R.C.A. (2005): Emergence/ re-emergence of Echinococcus spp. - a global update. Int. J. Parasitol., 35: 1205 - 1219

LOOS-FRANK, B. (1991): One or two intermediate hosts in the life cycle of Mesocestoides (Cyclophyllidea, Mesocestoididae)? Paraitol. Res., 77: 726 - 728

PAWlowski, Z. S., ECKERT, J., VUITTON, D. A., AMMANN, R. W., KERN, P. et al. (2001): Echinococcosis in humans: clinical aspects, diagnosis and treatment. In ECKERT, J., Gemmell, M. A., Meslin, F. X., PAwlowsi, Z. S. (Eds.): WHO/OIE manual of echinococcosis in humans and animals: a public health problem of global concern. World Organisation for Animal Health, Paris, pp. $20-71$

Romig, T., Kratzer, W., Kimmig, P., Frosch, M.., Gaus, W., Flegel,.W. A., Gottstein, B., Lucius, R., BecKH, K., KERN, P. (1999a): An epidemiologic survey of human alveolar echinococcosis in southwestern Germany. Am. J. 
Trop. Med. Hyg., 61: $566-573$

Romig, T., Bilger, B., Dinkel, A., Merli, M., MaCKENSTEDT, U. (1999b): Echinococcus multilocularis in animal hosts: new data from western Europe. Helminthologia, 36: 185 - 191

Schelling, U., Frank, W., Will, R., Romig, T., Lucius, R. (1997): Chemotherapy with praziquantel has the potential to reduce the prevalence of Echinococcus multilocularis in wild foxes (Vulpes vulpes). Ann. Trop. Med. Parasitol., 91: 179 - 186

Schweiger, A., Ammann, R. W., CAndinas, D., Clavien, P.-A., Eckert, J., GotTstein, B., Halkic, N., Muellhaupt, B., Prinz, B. M., Reichen, J., TARR, P. E., TORGERSON, P. R., DEPLAZES, P. (2007): Human alveolar echinococcosis after Fox Population Increase, Switzerland. Emerg. Infect. Dis. (Epub ahead of print)
Tackmann, K., Löschner, U., Mix, H., Staubach, C., ThulKe, H.-H., Ziller, M., ConRaths F .J. (2001): A field study to control Echinococcus multilocularis-infections of the red fox (Vulpes vulpes) in an endemic focus. Epidemiology and Infection, 127: $577-587$

Thoma, D., Romig, T., Heinel, S., Janko, C., Schreiber, T., König, A., Dinkel, A., Mackenstedt, U. (2004): Small towns in Germany: Echinococcus multilocularis and fox biology. Int. Arch. Hydatidosis, 35: 136

Veit, P., Bilger, B., Schad, V., Schäfer, J., FranK, W., LUCIUS, R. (1995): Influence of environmental factors on the infectivity of Echinococcus multilocularis eggs. Parasitology, 110: $79-86$ 